\title{
Variant Type of Stress Cardiomyopathy: Inverted Takotsubo Syndrome
}

\author{
Roberto Ramos Barbosa, ${ }^{1,2}$ Mayara da Silva, ${ }^{1}$ Marcelo Vaz de Mello Demian, ${ }^{2}{ }^{\circledR}$ Luiz Fernando Machado Barbosa1 $^{(\mathbb{D}}$ \\ Escola Superior de Ciências da Santa Casa de Misericórdia de Vitória (EMESCAM), ' ES - Brazil \\ Hospital Unimed Vitória, ${ }^{2}$ ES - Brazil
}

\section{Introduction}

Takotsubo syndrome (TTS), also known as stress cardiomyopathy, is a rare condition characterized by transient systolic and diastolic LV dysfunction, with akinesia of the apex and compensatory basal hyperkinesia, giving the heart the aspect of "apical ballooning", described for the first time in 1990 in Japan. ${ }^{1}$ Its clinical presentation mainly includes chest pain, which often has typical angina characteristics, and dyspnea, ${ }^{2}$ being an important differential diagnosis from a classic acute coronary syndrome (ACS).

TTS is observed predominantly among postmenopausal women, and the emotional stress is considered a precipitating factor in most studies. Its etiology is still controversial, and the excess of circulating catecholamine is the most acceptable mechanism..$^{2-5}$

Variant forms of TTS have been increasingly reported, ${ }^{6}$ among which are described the apical, mid-ventricular, basal, and focal types ${ }^{7}$ or the inverted Takotsubo syndrome (ITS), characterized by hyperdynamic apex and akinesia of the base; a morphological pattern opposite to the most common clinical manifestation of the disease.

In this case report, we present the diagnosis and the evolution of a rare variant form of stress cardiomyopathy: inverted Takotsubo syndrome.

\section{Keywords}

Takotsubo Cardiomyopathy/ complications; Takotsubo Cardiomyopathy/physiopathology; Takotsubo Cardiomyopathy/drug therapy; Psychological Stress; Heart Ventricles/diagnostic imaging; Echocardiography.
Case report

A physically active female aged 70 years of age, with no cardiovascular risk factors, was admitted to the cardiac emergency department, on $04 / 19 / 17$, complaining of chest pain with angina characteristics, with two hours of evolution, which started after emotional stress within her family. Her physical examination did not show significant alterations, with arterial oxygen saturation of $97 \%$, blood pressure of $142 / 74 \mathrm{mmHg}$ and a heart rate of 78 beats per minute. The ECG demonstrated sinus rhythm, a heart rate of 76 beats per minute and absence of ST-T segment changes. First troponin I dosage was $3.97 \mathrm{mg} / \mathrm{dl}$ (reference: $<0.4$ ) and CK-MB mass of $9.38 \mathrm{mg} / \mathrm{dl}$ (reference: $<5.4$ ). The diagnosis at admission was myocardial acute infarction (MAI) without ST segment elevation.

She was medicated with bisoprolol, enalapril, aspirin, ticagrelor, enoxaparin and pantoprazole, with improvement in chest pain. On $04 / 20 / 17$, she was submitted to a coronary coronary angiography, which revealed angiographically normal coronary arteries with no obstructive lesions (Figure 1). Left ventriculography showed systolic dysfunction with basal akinesia and apical hyperkinesia consistent with ITS (variant contractile pattern of stress cardiomyopathy) (Figure 2). Transthoracic echocardiography revealed akinesia of mid portion of anterior, septal, inferior and lateral LV walls, with hyperkinesis of the other walls, and estimated ejection fraction at $39 \%$, calculated with the Simpson's method.

Maintained in clinical treatment, the patient presented satisfactory intra-hospital evolution, without new episodes of angina or clinical instability. She was discharged on $04 / 22 / 17$, under use of aspirin and carvedilol, and remained asymptomatic during the 30-day clinical follow-up. 

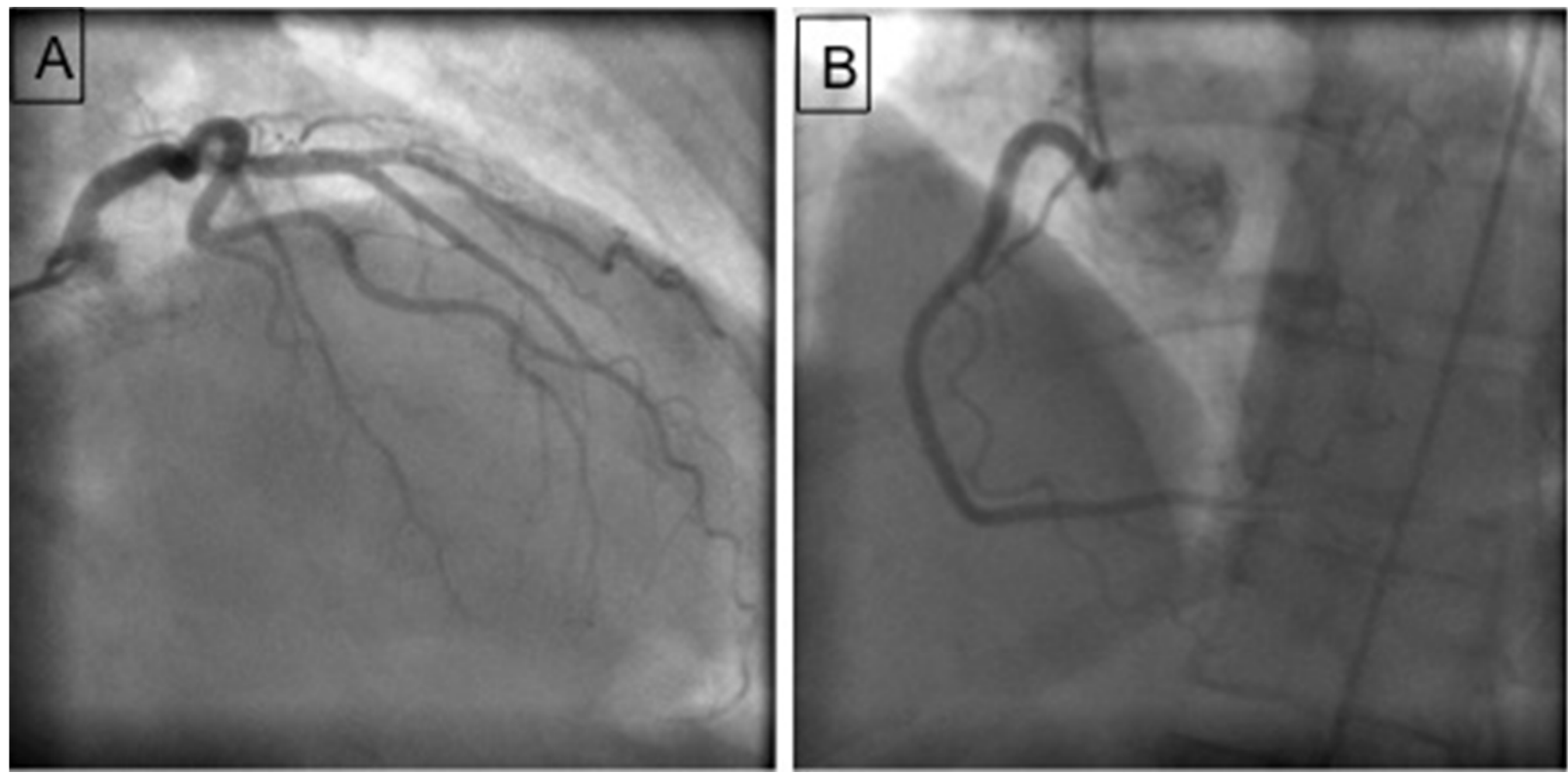

Figure 1 - Coronary angiography showing nonobstructive angiographically normal coronary arteries. A: left coronary artery; B: right coronary artery.

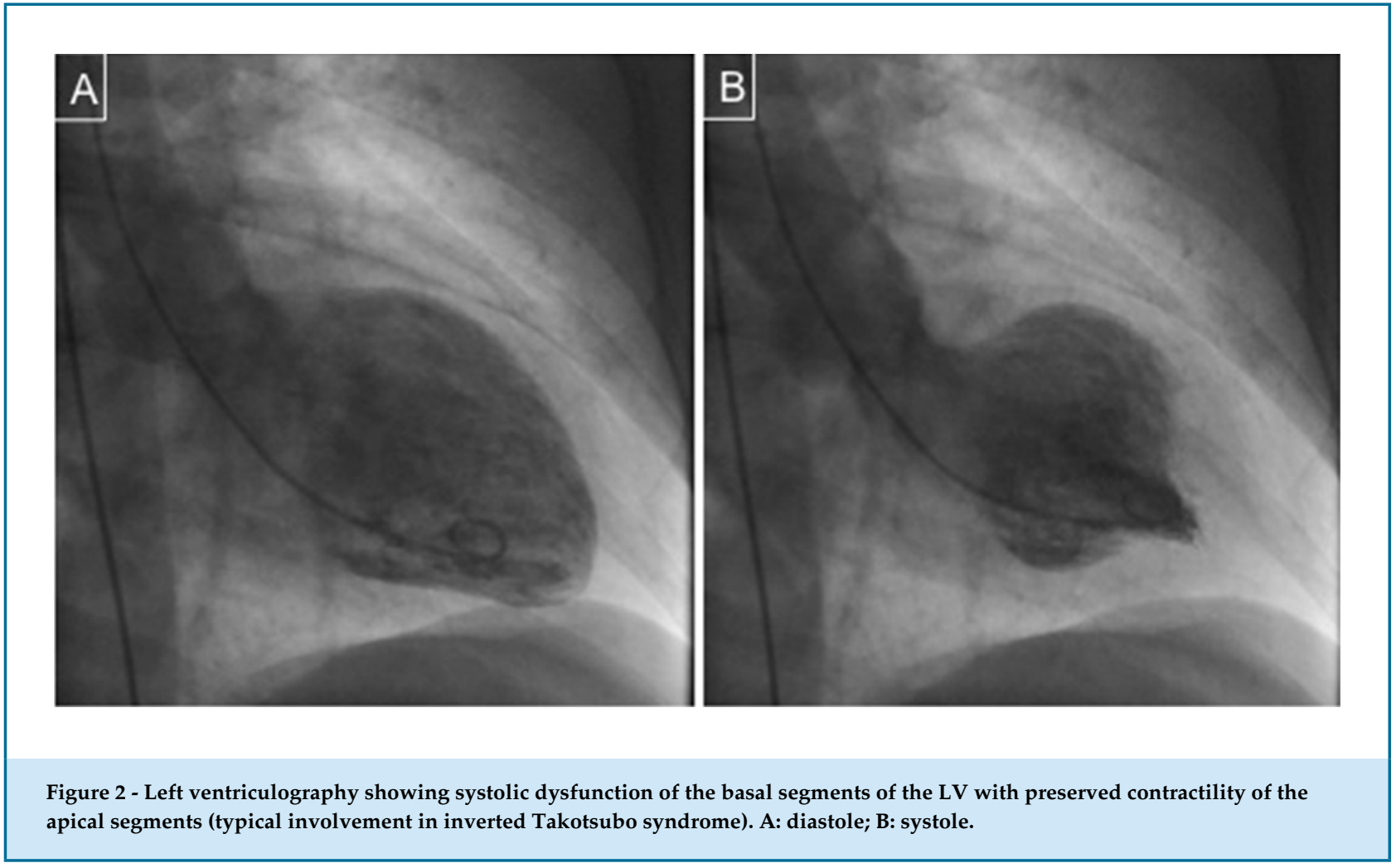




\section{Discussion}

Clinically indistinguishable from classic ACS, TTS can present with or without variable changes on ECG, ${ }^{2}$ as well as with elevation in myocardial lesion markers, ${ }^{3,8}$ as seen in this report. Therefore, although TTS may be suspected through epidemiological data (postmenopausal women) and emotional stress as an event trigger, it may be difficult to distinguish TTS from ACS due to atherothrombosis in the initial assessment. ${ }^{3}$

TTS may also be triggered, although less frequently, by positive and pleasant emotions, which can make it even more difficult to identify. While the clinical presentation is usually similar, a greater prevalence of midventricular involvement is observed in cases of TTS resulting from positive emotions, compared to TTS caused by negative emotions (35.0\% vs. $16.3 \%$; $\mathrm{p}=0.030) .{ }^{9}$

Coronary angiography and left/echocardiographic ventriculography showed normal coronary arteries and involvement of ventricular walls which extended beyond one specific arterial territory. These conditions, associated with evidence of emotional or physical stress as precipitating factors, are considered criteria for the diagnosis of TTS, although not exclusively. ${ }^{1,3}$ This report brings a case of ITS in which the diagnosis was made soon after the coronary anatomy had been defined on coronary angiography, confirmed by the classic appearance revealed by left ventriculography.

Among the causes of non-obstructive coronary failure, TTS has presented increasing incidence, with variable evolution. The management of this syndrome with angiotensin converting enzyme inhibitors, angiotensin receptor blockers and beta-blockers is also reported; the latter, particularly due to evidence of adrenergic excess in its physiopathology. However, the benefits of these drugs to treat TTS and its variations lack solid scientific evidence. ${ }^{8}$

The variant forms of TS, such as ITS, still have no wellestablished occurrence, clinical course or recurrence index in the world literature. Population differences are little known. A recent study has shown four morphological types of TTS: apical form, mid-ventricular form, basal (or inverted) form and focal form. ${ }^{3}$ The estimated incidence of the different ventricle involvements were, respectively, $81.7 \%, 14.6 \%, 2.2 \%$ and $1.5 \%$.

The ITS is distinguished from the typical form through imaging tests that reveal basal akinesia or hypokinesia with apical LV compensatory hyperkinesia. Even though the cause of this variation is not defined yet, it has been proposed that its morphology is a direct result of the apex containing a higher density of adrenoreceptors in postmenopausal women, predisposing this group to this type of involvement. ${ }^{6}$ In spite of these data, the reason why this type is rarer than the classical form of TTC is unknown. Some cases of ITS reported were considered secondary to pheochromocytoma, but this association, as well as its mechanism, are not cleared yet. ${ }^{10,11}$

It is worth highlighting that TTS is just one among several possible causes of myocardial infarction with nonobstructive coronary arteries (MINOCA). Other possibilities should be considered, such as coronary spasm, rupture of atherosclerotic plaque, spontaneous coronary dissection, microvascular disorders, coronary embolism, use of sympathomimetic agents, myocarditis, cardiotoxic drugs and cardiac trauma. ${ }^{12}$

A detailed analysis is recommended in unclear cases of MINOCA, with special attention to indications for magnetic cardiac resonance, ${ }^{12,13}$ since it can distinguish types and patterns of myocardial lesions and is useful to confirm or rule out myocarditis. In addition, it can provide the basis for pathophysiological reasoning and clinical conduction in each case. ${ }^{12,14}$ Other complementary methods may be necessary according to individual clinical findings, such as intracoronary ultrasound and echocardiogram with microbubbles. ${ }^{15}$

Once considered a syndrome of benign course, because of spontaneous reversion of ventricular dysfunction within weeks in most cases, the acute phase of TTS can lead to complications and death due to left ventricular outflow tract obstruction, ventricular arrhythmias, cardiogenic shock, ventricular rupture, ventricular thrombus formation and embolization. ${ }^{7}$ In the long run, there may be TTS recurrences in about $14 \%$ of cases, and high mortality rate, usually attributed to comorbidities often found in TTS, such as neoplasms, intracranial hemorrhage, psychiatric disorders and lung diseases. ${ }^{16,17} \mathrm{Clinical}$ differences related to the subtypes and variations of TTS require more studies to be clarified, in order to obtain more long-run data for the different types of involvement.

We reported a rare variant form of TTS: a diagnosis that has gained attention because of the growing stress in the modern world and increasing life-expectancy. Future scientific data shall turn to more accurate identification of possible patterns, the genetic changes involved, determination of degree of severity and more appropriate therapy. 


\section{Author contributions}

Conception and design of the research: Barbosa RR, Barbosa LFM. Acquisition of data: Barbosa RR, Silva M, Demian MVM. Analysis and interpretation of the data: Barbosa RR, Silva M. Writing of the manuscript: Barbosa RR, Silva M. Critical revision of the manuscript for intellectual content: Barbosa RR, Barbosa LFM.

\section{Potential Conflict of Interest}

No potential conflict of interest relevant to this article was reported.

\section{References}

1. Sato HT, Uchida T, Dote K, Ishihara M. Tako-tsubo-like left ventricular dysfunction due to multivessel coronary spasm. In: Kodama K, Haze K, Hori M. (editors). Clinical aspect of myocardial injury: from ischemia to heart failure. Tokyo: Kagakuhyoronsha Publishing; 1990. p. 56-64.

2. Hurst RT, Prasad A, Askew JW 3rd, Sengupta PP, Tajik AJ. Takotsubo cardiomyopathy: a unique cardiomyopathy with variable ventricular morphology. JACC Cardiovasc Imaging. 2010;3(6):641-9.

3. Templin C, Ghadri JR, Diekmann J, Napp LC, Bataiosu DR, Jaguszewski $\mathrm{M}$, et al. Clinical features and outcomes of Takotsubo (stress) cardiomyopathy. N Engl J Med. 2015;373(10):929-38

4. Nóbrega S, Brito D. [The "broken heart syndrome": state of the art]. Rev Port Cardiol. 2012;31(9):589-96.

5. Brunetti ND, Santoro F, De Gennaro L, Correale M, Gaglione A, Di Biase M. Drug treatment rates with beta-blockers and ACEinhibitors/angiotensin receptor blockers and recurrences in Takotsubo cardiomyopathy: a meta-regression analysis. Int J Cardiol. 2016 Jul 1;214:340-2.

6. Ramaraj R, Movahed MR. Reverse or inverted Takotsubo cardiomyopathy (reverse left ventricular apical ballooning syndrome) presents at a younger age compared with the mid or apical variant and is always associated with triggering stress. Congest Heart Fail. 2010;16(6):284-6.

7. Sharkey SW, Windenburg DC, Lesser JR, Maron MS, Hauser RG, Lesser JN, et al. Natural history and expansive clinical profile of stress (takotsubo) cardiomyopathy. J Am Coll Cardiol. 2010;55(4):333-41.

8. Santoro F, Ieva R, Musaico F, Ferraretti A, Triggiani G, Tarantino N, et al. Lack of efficacy of drug therapy in preventing takotsubo cardiomyopathy recurrence: a meta-analysis. Clin Cardiol. 2014;37(7):434-9.

9. Gadhri JR, Sarcon A, Diekmann J, Bataiosu DR, Cammann VL, Jurisic S, et al; InterTAK Co-investigators. Happy heart syndrome: role of positive emotional stress in takotsubo syndrome. Eur Heart J. 2016;37(37):2823-9.

\section{Sources of Funding}

There were no external funding sources for this study.

\section{Study Association}

This study is not associated with any thesis or dissertation work.

\section{Ethics approval and consent to participate}

This article does not contain any studies with human participants or animals performed by any of the authors.

10. Gervais MK, Gagnon A, Henri M, Bendavid Y. Pheochromocytoma presenting as inverted Takotsubo cardiomyopathy: a case report and review of the literature. J Cardiovasc Med (Hagerstown). 2015;16 Suppl 2:S113-7.

11. Kim S, Yu A, Filippone LA, Kolansky DM, Raina A. Inverted-Takotsubo pattern cardiomyopathy secondary to pheochromocytoma: a clinical case and literature review. Clin Cardiol. 2010;33(4):200-5.

12. Agewall S, Beltrame JF, Reynolds HR, Niessner A, Rosano G, Caforio $\mathrm{AL}$, et al; WG on Cardiovascular Pharmacotherapy. ESC working group position paper on myocardial infarction with non-obstructive coronary arteries. Eur Heart J. 2017;38(3):143-53.

13. Leurent G, Langella B, Fougerou C, Lentz PA, Larralde A, Bedossa $\mathrm{M}$, et al. Diagnostic contributions of cardiac magnetic resonance imaging in patients presenting with elevated troponin, acute chest pain syndrome and unobstructed coronary arteries. Arch Cardiovasc Dis. 2011;104(3):161-70.

14. Tornvall P, Gerbaud E, Behaghel A, Chopard R, Collste O, Laraudogoitia $\mathrm{E}$, et al. A meta-analysis of individual data regarding prevalence and risk markers for myocarditis and infarction determined by cardiac magnetic resonance imaging in myocardial infarction with non-obstructive coronary artery disease. Atherosclerosis. 2015;241(1):87-91.

15. Alfonso F, Paulo M, Dutary J. Endovascular imaging of angiographically invisible spontaneous coronary artery dissection. JACC Cardiovasc Interv. 2012;5(4):452-3.

16. Stiermaier T, Moeller C, Oehler K, Desch S, Graf T, Eitel C, et al. Longterm excess mortality in takotsubo cardiomyopathy: predictors, causes, and clinical consequences. Eur J Heart Fail. 2016;18(6):650-6.

17. Redfors B, Vedad R, Angerås $\mathrm{O}$, Råmunddal T, Petursson $\mathrm{P}$, Haraldsson $\mathrm{I}$, et al. Mortality in takotsubo syndrome is similar to mortality in myocardial infarction-a report from the SWEDEHEART registry. Int J Cardiol. 2015 Apr 15;185:282-9. 